AperTO - Archivio Istituzionale Open Access dell'Università di Torino

\title{
Influence of Massive and Long Distance Migration on Parasite Epidemiology: Lessons from the Great Wildebeest Migration
}

\section{This is the author's manuscript}

Original Citation:

Availability:

This version is available http://hdl.handle.net/2318/1725552

since 2020-01-28T11:07:00Z

Published version:

DOI:10.1007/s10393-016-1156-2

Terms of use:

Open Access

Anyone can freely access the full text of works made available as "Open Access". Works made available under a Creative Commons license can be used according to the terms and conditions of said license. Use of all other works requires consent of the right holder (author or publisher) if not exempted from copyright protection by the applicable law. 


\section{Influence of Massive and Long Distance Migration on Parasite Epidemiology: Lessons from the Great Wildebeest Migration}

Domnic Mijele, 1 Takashi Iwaki,2 Patrick I. Chiyo, 1 Moses Otiende, 1 Vincent Obanda, 1

Luca Rossi,3 Ramon Soriguer,4 and Samer Angelone-Alasaad 4,5

1Forensic and Genetics Laboratory, Kenya Wildlife Service, P.O Box 40241-00100 Nairobi, Kenya

2Meguro Parasitological Museum, 4-1-1 Shimomeguro, Meguro-ku, Tokyo 153-0064, Japan

3Dipartimento di Scienze Veterinarie, Universita` degli Studi di Torino, L.go Braccini 1, I-10095 Grugliasco, Italy

4Estacio'n Biolo'gica de Doñana, Consejo Superior de Investigaciones Científicas (CSIC), Avda. Ame'́rico Vespucio s/n 41092,

Seville, Spain

5Institute of Evolutionary Biology and Environmental Studies (IEU), University of Zu"rich, Winterthurerstrasse 190, 8057 Zurich,

Switzerland

Abstract: Very little is known about the influence of massive and long distance migration on parasite epidemiology.

Migration can simultaneously minimize exposure to common parasites in their habitats and increase exposure to novel

pathogens from new environments and habitats encountered during migration, while physiological stress during long distance movement can lead to immune suppression, which makes migrants vulnerable to parasites. In this paper, we investigated the diversity, prevalence, parasite load, co-infection patterns and predilection sites of adult gastrointestinal helminths in 130 migratingwildebeests and tested for their relationwith animal age, sex andmigration time (which also could indicate different migration routes), and compared them with the non-migratory wildebeest. Surprisingly, only four parasite species were found, Oesophagostomum columbianum, Haemonchus placei, Calicophoron raja and Moniezia expansa, which were lower than in non-migratory wildebeest reported in the literature. These parasites were generalists, infecting livestock, and suggests that wildebeest and livestock, because of their interaction duringmigration, have a crossinfection risk. There was a negative relation between parasites diversity, prevalence and intensity of infection, and host age, which suggests thatwildebeests acquire protective immunity against these parasites as they get older. Prevalence and intensity of infection were higher among wildebeest crossing the Mara Bridge (early migrants) compared to those crossing the Serena (late migrants), which suggests that early migrants (or migrants originating from different areas) have varying infection intensities. The prevalence and intensity of infection were higher in males compared to females and may be due to ecological, behavioural, or physiological differences between males and females. Our findings compared to those of previous studies suggest thatmigration may provide amechanism tominimize exposure of hosts to common parasites through migratory escape, but this result awaits examination of helminths epidemiology of nonmigratory wildebeests from areas of migrant origins. The potential parasitic cross-infection between wildebeests and

livestock is a real risk to be taken into account in the management of wildebeest migration corridors.

Electronic supplementary material: The online version of this article (doi:10.1007/

s10393-016-1156-2) contains supplementary material, which is available to authorized

users.

Published online: August 23, 2016

Correspondence to: Domnic Mijele, e-mail: dmijele@kws.go.ke; sameralasaad@hot

mail.com

EcoHealth 13, 708-719, 2016

DOI: $10.1007 / \mathrm{s} 10393-016-1156-2$

\section{Original Contribution}

2016 International Association for Ecology and Health

Keywords: gastrointestinal helminthes, Serengeti-Mara ecosystem, Oesophagostomum columbianum, Haemonchus placei, Calicophoron raja, Moniezia expansa, co-infection,

parasite competition, parasite predilection sites, parasite load

ABBREVIATIONS

MMNP Masai mara national reserve

GIT Gastro-intestinal tract

GLM General linear model

KWS Kenya wildlife service

INTRODUCTION

Long distance migration, common in several species of birds, butterflies and mammals can affect the diversity, prevalence, and burden of parasites and pathogens in migratory populations of these species. Parasites epidemiology of migrant animals is of pivotal interest, nonetheless very little is known regarding parasite prevalence and diversity in migratory populations of many mammalian species, including the blue wildebeest (Connochaetes taurinus),

a bovid species known to migrate annually from the

Serengeti in Tanzania to Masai Mara in Kenya covering approximately $3000 \mathrm{~km}$ in search of adequate pasture and water.

Long distance migration is speculated to have both negative and positive influences on pathogen transmission, diversity, prevalence and parasite burden/load within migrants depending on host migratory behaviour and pathogen 
traits (Altizer et al. 2011). In terms of the negative consequences of long distance migration, migrants may come into contact with different habitats with different parasite faunas and hosts species (Altizer et al. 2011). Migrants are particularly likely to acquire new environmentally transmitted parasites such as gastro-intestinal helminths, whose prevailing mode of transmission is the oral faecal route. In addition, the energetic demands of migration can compromise host immunity, enhancing susceptibility to infection and intensifying the impacts of disease. Long distance migration is energetically costly, and many wildebeest die from physical exhaustion, drown as they cross the Mara River and are attacked by predatory crocodiles. Like in other vertebrate species, such physical exhaustion during migration is physiologically stressful, and migration-induced stress may cause immune suppression thereby increasing infection risk with different parasites and pathogens.

Theoretical model predictions suggests that long distance migration can reduce disease prevalence through migratory escape from parasite invested areas and selective mortality on parasitized individuals during migration (Avgar et al. 2013; Johns and Shaw 2016). There is increasing empirical support for these theoretical predictions; long distance migration may enhance avoidance of parasite, even the selection of parasite-free habitats, as suggested in shorebirds (Piersma 1997) and reindeer (Folstad et al. 1991). The parasite fauna of non-migratory wildebeest is well documented (Horak et al. 1983) but nothing is known about the parasites of migratory wildebeest. Parasite interactions and co-infections may also affect the host's immune response leading to immune suppression or cross-reactive immune responses (Pedersen and Fenton 2007; Cobey and Lipsitch 2013). Currently, insights into host-parasite interactions are still largely based on studies involving single parasite species infecting single hosts. Yet, in the real world, hosts are often infected by numerous parasite genotypes of the same or different species simultaneously (Ulrich and Schmid-Hempel 2012). Since migratory wildebeests are likely to harbour multiple helminth infections and fresh carcasses were available from annual natural deaths, they provided an opportunity to investigate the epidemiology of the most common gastrointestinal parasites and parasite predilection and co-infection patterns within hosts. These patterns may help reveal parasite interactions like competition for host resources or attachment sites within the host (Cattadori et al. 2007; Mideo 2009) or interactions between parasites and the host's immune system. The literature that deals directly Influence of Massive and Long Distance Migration on Parasite Epidemiology 709 with the distribution of helminths in the gastrointestinal tract of vertebrates is relatively limited (Crompton 1973). Studies on parasite co-infection have mainly focused on exposure risk factors and little attention has been given to patterns of parasite predilection sites within hosts and its relationships with patterns of co-infection since this may reveal aspects of parasite ecology such as competition for attachment sites or resources within host species (Cattadori et al. 2007; Mideo 2009). Interactions between parasites may be indirectly manifested via the host's immune suppression by one parasite benefiting another (Graham 2008; Fenton and Perkins 2010; Telfer et al. 2010; Hawley and 
Altizer 2011).

This study aims to (1) evaluate the parasite diversity, and prevalence and intensity of infection of adult helminths in migratory wildebeests, (2) test the influence of host age, sex and migration time (which could also mean different migration routes) on helminth diversity, and prevalence and intensity of infection, (3) determine the co-infection patterns, (4) determine the predilection sites of helminths in the gastrointestinal tract of the wildebeests, and (5) assess the general putative influence of massive and long distance migration on parasite epidemiology.

\section{Materials and Methods}

Study Area

The study was conducted in the Masai Mara National Reserve (MMNR) located in southwest Kenya along the Kenya-Tanzania border (1_100000 and 2_100000S, 34_140500 and 36_100000E). MMNR occupies an area of approximately 1510 square Kilometers and has a high density of wildlife populations including large mammals such as African elephants, lions, leopards, African buffaloes, black rhinoceros, wildebeests and several antelope species (Mijele et al. 2013). The reserve is contiguous with the Serengeti National Park on the Tanzanian side and is traversed by the Mara River flowing from the Mau escarpments across the reserve into Serengeti and drains in Lake Victoria. The MMNR and Serengeti form part of the blue wildebeests' migration route. Wildebeest migrating into the Mara use three major crossing areas: Mara Bridge (where the early migrant wildebeest cross the river), Serena (where the late migrants cross the river) and Governors (Fig. 1). Post-Mortem Procedures and Parasite Sampling Post-mortem examination was carried out on 130 migratory wildebeests that drowned along the Mara River between 2010 and 2012 at two different locations along the Mara River (Fig. 1). Sex, age and species and number of gastrointestinal parasites were recorded from all wildebeest that were dissected. This sample had 66 adults, 13 subadults, and 51 juveniles, comprising 65 females and 65 males. Wildebeest carcasses were retrieved from the river using an anchor attached to a rope. Each carcass was put on dorsal recumbence and cut open on the ventral part of the abdomen along the linea alba to access the abdominal contents. Once the abdomen was opened, prestomachs, abomasum, small and large intestines were ligated at omaso-abomasal, abomaso-duodenal and ileo-caecal junctions to prevent parasites spilling from one part to another. The ligated gastrointestinal tracts were processed for helminth recovery as described by Horak et al. (1982).

Specifically, contents from each section of the gastro-intestinal tract were washed through a sieve $0.5 \mathrm{~mm}$. All

material that was not washed was first examined by eye and all visible adult worms were isolated and counted. Secondly, we examined all the contents using a hand held 910 magnifying glass and all tiny worms were picked and isolated from each section of the gastrointestinal tract. Worms were first classified based on gross morphology and then counted. Several worm samples were collected into tubes according to the site in the gastrointestinal tracts it was collected from and according to our field ID. Worm samples were preserved in $70 \%$ ethanol in the field and a representative sample of this field collection based on our 
field IDs and predilection sites were sent for identification at Meguro Parasitological Museum, Japan.

Age Estimation of Wildebeest Carcasses

The age at death of wildebeest was estimated based on horn length and shape, body size and pelage colour and tooth wear. Detailed relationships between horn length and shape and wildebeest age are described in Talbot and Talbot (1963) and a detailed description of assigning age based on tooth wear patterns is available elsewhere (Attwell 1980). Juveniles were classified as animals 1 year or less; subadults were classified as animals between 1 and 2.5 years of age. Animals above 2.5 years were classified as adults. 710 D. Mijele et al.

Figure 1. Map of Masai Mara National Reserve and associated protected areas. Influence of Massive and Long Distance Migration on Parasite Epidemiology 711

Morphological Identification of Parasites and Species Diversity

In the lab, the parasite samples were washed in water overnight in order to remove the fixative, relax internal organs and enhance clear examination of internal organs on a microscope. The cestodes and trematodes were then placed between two glass slides tightened by cotton thread and left to flatten in 50\% acetic acid for 1 week, to about $1 \mathrm{~mm}$ thick. The cestodes were stained by alum carmine, dehydrated in ethanol, cleared by xylene and mounted by Canada balsam. The trematodes were unstained and cleared by glycerine. The nematodes were directly cleared by glycerine. All specimens were observed and identified at 50-400 magnification under a light microscope.

Statistical Analysis Influence of Host Sex, Age and Migration Time (and the Interaction Between these Factors) on Prevalence and Intensity of Infection and Diversity of Adult Gastro-Intestinal Parasites

Fisher Exact test was used to determine the associations between prevalence of infection and animal sex, age and migration time.

A generalized linear model with a Poisson family and an identity link function was used to test the hypothesis that age, sex and migration time (represented by location of entry into the Mara National Reserve), or any interaction between these factors are important predictors of gastrointestinal helminths infection intensity. We used the total count of adult parasites of each species (or all species total counts combined) as a dependent variable.

In the case of parasite diversity, we used a proportional odds ordinal logistic regression model, where the number of parasite species (parasite diversity) by wildebeest was used as a dependent variable. The final and best model was selected based on AIC and these are the models reported in the results.

Predilection Sites of Adult Gastrointestinal Helminths We examined the presence and co-infection possibility of common helminth parasite species in the various parts of the gastrointestinal tract. For testing this association, we used a v2 test.

All statistical analyses were performed using $\mathrm{R}$ software version 3.2.0 (R Core Team 2014).

Results

Parasite Species Identification and Diversity

Four species (a cestode, a trematode and two nematodes) 
were identified in the studied wildebeests. The single cestode belonged to the genus Moniezia of the family Anoplocephalidae (Beveridge 1994). From the arrangement of interproglottidal glands (Schmidt 1986), this cestode was classified as Moniezia expansa (Fig. S1a, b).

The trematode belonged to the genus Calicophoron of the family Paramphistomidae (Jones 2005). We observed small tegumental papillae arranged densely around the genital atrium, that is typical of Calicophoron raja (Eduardo 1983). The body length was approximately $7 \mathrm{~mm}$ and egg size was $145-150 \mathrm{~lm}$, consistent with the description of this species (Fig. S1c-e).

Based on the structure of head and uterus, one of the nematodes was found to belong to the genus Oesophagostomum of the family Chabertiidae (Lichtenfels 1980). According to key to the species (Popova 1958), this nematode was identified as O. columbianum (Fig. S1f-h). Body length of this sample was $12.3-13.9 \mathrm{~mm}$ in males and $16.8-20.1 \mathrm{~mm}$ in females. The number of outer/inner crowns in head was about 20/40. Spicule length was 752 $886 \mathrm{~lm}$. Distance from vulva to tail end was 1.22

$1.39 \mathrm{~mm}$. The whole body size, lengths of spicules and position of vulva are coincident with the description of this species.

The other nematode belonged to the genus Haemonchus of the family Trichostrongylidae (Durette-Desset 1983), based on the structure of bursa and spicules of the male. The morphological measurements of our samples were consistent with the description for $\mathrm{H}$. placei. Body length was $13.1-13.7 \mathrm{~mm}$ in the males and $22.5-22.8 \mathrm{~mm}$ in females. The right and left spicule length were 465-467, and 466-473 lm long, respectively (Fig. S1i, j). Gubernaculum length was 224-232 $\mathrm{lm}$ and the distance from vulva to tail end in a female was $4.12-4.28 \mathrm{~mm}$. In addition, according to Lichtenfels et al. (1994), who studied the morphology of $\mathrm{H}$. contortus and related species, the present nematode fits Haemonchus placei description, because of the number of cuticular ridges or synlophe $(34 \mathrm{in} \mathrm{H}$. placei 712 D. Mijele et al.

34), extending posteriorly only to the end of the anterior quarter of the body.

Predilection Sites of Adult Gastrointestinal

Helminths

Chi square tests analyses revealed significant associations between parasite species presencewith distinct sections of the gastrointestinal tract (Fig. S2). M. expansa was significantly more present in the small intestines $(\mathrm{v} 2=90.93, \mathrm{df}=5$, $P$ _ 0.001), while $O$. columbianum was significantly more in the large intestines $\left(\mathrm{v}_{2}=275.58, \mathrm{df}=5, \mathrm{P}_{-}\right.$0.001) than any other section of the gastro-intestinal tract. $\mathrm{H}$. placei was more frequently found in the abomasum than in any other part of the gastro-intestinal tract $\left(\mathrm{v}_{2}=95.31, \mathrm{df}=5, \mathrm{P}_{-} 0.001\right)$. C. raja was predominantly found in the rumen $\left(\mathrm{v}_{2}=5.03\right.$, $\mathrm{df}=5, \mathrm{P}=0.4127)$. There was no significant overlap in terms of predilection sites among the common parasites encountered in wildebeest (Fig. S2).

Helminths Prevalence, Intensity and Co-infection Seventy two percent (94/130) of the wildebeests sampled were positive for one or more of the aforementioned major gastro-intestinal parasites. Males were more frequently affected, $80 \%(52 / 65)$, than females, $64.62 \%$ (42/65), and the 
difference was statistically significant $(P=0.023)$. Young

animals (1-5 years old) were more frequently infected

$(83.82 \%)$, than old animals (6-10 years old) $(58.18 \%)$, and

this result was also statistically supported $(P=0.002)$.

Wildebeest crossing through Mara Bridge had higher

prevalence of helminth infections $(86.67 \%, 13 / 15)$ than

those crossing through Serena $(70.43 \%, 81 / 115)$; however

the difference was not statistically supported.

Table 1. Selected GLM Models Based on AIC for Predicting Intensity of Infection for All Parasites (Total Parasite Load),

Haemonchus

placei, Moniezia expansa, Oesophagostomum columbianum and Calicophoron raja Using Crossing Area (Representing

Migration Time, or

Different Migration Routes), Age and Sex of the Wildebeest as Explanatory Variables in the Different Models.

Parasite load Estimate Std. error Z-value Pr $(>|z|)$ Null deviance df1 Residual

deviance

df2 AIC Explained

deviance

Total load of parasite 3672.212222831192588 .60 .3783

(Intercept) $3.9070 .07949 .532<2 \mathrm{e}-16$

Crossing area $-2.2960 .061-37.689<2 \mathrm{e}-16$

Age 0.3960 .0665 .9790 .000

Sex $-0.0310 .010-3.1950 .001$

Haemonchus placei 146.91122130 .73119138 .730 .1101

(Intercept) 0.6970 .8360 .8340 .404

Crossing area $-1.1740 .740-1.5880 .112$

Age $-0.2230 .075-2.9950 .003$

Sex 0.4970 .4381 .1360 .256

Moniezia expansa 102.412 12273.60311981 .6030 .2813

(Intercept) -16.273 1924.553 -0.008 0.993

Crossing area 16.6851924 .5530 .0090 .993

Age $-0.7560 .299-2.5280 .012$

Sex $-0.7180 .574-1.2510 .211$

Oesophagostomum columbianum 170.12122167 .08119175 .080 .0179

(Intercept) 0.5380 .7800 .6900 .490

Crossing area $-0.3150 .711-0.4430 .658$

Age $-0.0910 .057-1.6060 .108$

Sex 0.0420 .3750 .1130 .910

Calicophoron raja 124.20012289 .10411997 .1040 .2826

(Intercept) $-1.9650 .979-2.0070 .045$

Crossing area $-2.5380 .940-2.7010 .007$

Age 0.4550 .1064 .2840 .000

Sex 0.7860 .5481 .4340 .152

Influence of Massive and Long Distance Migration on Parasite Epidemiology 713

The prevalence of adult gastrointestinal helminths in

wildebeest was high for $O$. columbianum at $46.2 \%(n=60)$

and lower for $\mathrm{H}$. placei at $29.2 \%(\mathrm{n}=38)$, C. raja $20 \%$

$(n=26)$ and $M$. expansa $14.6 \%(n=19)$. Parasite load

(worm burden) was variable among infected wildebeests

(range: 1-271 adult parasites). The mean \pm (SD) and

median worm burden were $13 \pm(34)$, and four worms per

individual host, respectively.

The prevalence of single infections was $38.46 \%$. The

prevalence of concurrent infections with two, three and

four parasites was $26.15,5.38$ and $2.31 \%$, respectively, while

$27.69 \%$ of the wildebeests were not infected by any adult

helminths. Concurrent infection of hosts with two, three or

four parasites was not significantly different from random

expectation $(\mathrm{v} 2=6.019, \mathrm{df}=3, \mathrm{P}=0.111)$.

Intensity of Infection with Adult Helminths in

Relation to Host Sex, Age and Crossing Time

When dealing with each parasite species separately, the best

model based on AIC number, revealed that there was a

notable effect of age on intensity of infection for most parasites

in wildebeests (Table 1). The infection of $\mathrm{H}$. placei, and $\mathrm{M}$.

expansa was significantly higher in young animals $(<2$ years 
old) compared to adult wildebeests ( $>3$ years old), but

intensity of infectionwith C. raja was higher in adult wildebeest,

compared to the young ones. Migration time (Crossing Area)

was also significant, with wildebeest crossing through Mara

Bridge having a higher intensity of infection than Serena.

However, there was no effect of age, sex and migration time on

the infection for O. columbianum (Table 1).

Figure 2. The influence of sex, age (in years) and wildebeest crossing area (representing migration time and/or different migration routes) on

adult infection intensity in migratory wildebeests.

Table 2. Coefficients of Logistic Regression Model and Intercepts for Each Level of Ordered Response Showing the Variation in Number of Parasite Species Infecting Wildebeests.

Variables Coefficients Std. error t value $P$ value

Age - $0.13010 .0532-2.4480 .0144$

Sex (male vs female) 0.29560 .340 .86940 .3846

Area crossing (serena vs mara) -1.2818 0.6546 -1.958 0.0502

Intercepts

$0 \mid 1-2.60480 .7417-3.51180 .0004$

$1 \mid 2-0.86460 .7108-1.21640 .2238$

$2 \mid 30.96180 .73851 .30220 .1928$

$3 \mid 42.25650 .87182 .58840 .0096$

Statistically significant $P$ values are shown in italics

714 D. Mijele et al.

The best Generalized Linear models, based on AIC

number, revealed that infection for all parasites combined was higher in juveniles compared to adults and sub-adults In addition, wildebeests crossing through the Mara bridge had higher infection than wildebeests crossing from Serena, and males were more infected compared to females (Fig. 2). The final models did not include any interactions between variables.

Diversity of Adult Gastro-Intestinal Helminths in

Relation to Host Sex, Age and Crossing Time

A proportional odds logistic regression model fitted to an ordered factor response (number of parasite species) revealed that the number of parasite species in a wildebeest was predicted by animal age and migration time (Table 2).

The younger the animal, the more parasite species it harboured (Fig. 3). Wildebeests sampled from Serena had higher parasite diversity than wildebeests crossing from Mara Bridge (Fig. 2).

\section{DISCUSSION}

Parasite Predilection Sites and Co-infection

Adult parasites recovered from the wildebeests occupied different parts of the gastrointestinal tract with no overlap in predilection sites among parasites. Predilection sites are largely consistent with similar parasites in domestic animals (Sutherland and Scott 2009; Roeber et al. 2013).

Co-infections among the four common wildebeest parasites were random association. This result was expected given that the common parasites do not compete for predilection sites in the hosts. Numerous experimental studies have investigated and confirmed the existence of negative and synergistic interactions among parasites (Kloosterman et al. 1984, 1990; Kloosterman and Frankena 1988; Dobson et al. 1992; Dobson and Barnes 1995; Ploeger et al. 1995), but there is little empirical evidence to suggest that these interactions occur in the wild.

Figure 3. Probability of infection with different species of helminthes as a function of age in wildebeests.

$\mathrm{X}$ animal ages (years), and the 
short lines at the $\mathrm{X}$-axes represent

the number of studied animals

from each age class. Y Probability

of being infected. Sub-panels show

increasing parasite diversity ranging

from 0 (no infection) to 4

parasite species.

Influence of Massive and Long Distance Migration on Parasite Epidemiology 715

Gastrointestinal Helminths Diversity

The diversity of the adult helminths infecting migratory

wildebeests was surprisingly low, and the four identified species were just a subset of the larger number infecting non-migratory blue wildebeests in South Africa (Horak et al. 1983; Junker et al. 2014). The apparently low diversity could be an artefact of not sampling micro-parasites, or mirror differences in ecology between the Masai MaraSerengeti ecosystem where migrants were sampled, and South Africa where most studies of non-migratory wildebeest have been conducted. However, when we compared gastrointestinal macro-parasites detectable by visual inspection in non-migratory wildebeests in Kruger National Park, they had a higher parasite diversity consisting of 12 species from 7 genera (Horak et al. 1983). The low diversity of parasites in migratory wildebeests observed in this study is consistent with the hypothesis that migration helps in escaping parasite build up, as observed in other migratory mammals (Hausfater and Meade 1982; Folstad et al. 1991). Further studies of parasite diversity of local sympatric wildebeests are needed to definitively answer the question of whether the long distance wildebeest migration is beneficial to hosts in terms parasite avoidance. All four helminths recovered from the gastrointestinal tract of the migratory wildebeests had relatively low infection intensities and, quite surprisingly, were generalist species that commonly infect livestock (Dube et al. 2004; Tariq et al. 2008). Helminths recovered from migrating wildebeest in this study could result from cross-infection from the domestic reservoirs along pastoral landscapes that dominate the wildebeest migratory routes (Dash 1973; Nwosu et al. 1996, Lone et al. 2011; Junker et al. 2014). The relative rarity of C. raja may be related to the scarcity of swampy areas required for the survival of intermediate snail host on the migratory pathways of wildebeest. $O$. columbianum and $\mathrm{H}$. placei were the most prevalent parasites in the studied wildebeests signifying their importance in the Masai Mara-Serengeti wildlife areas or in migratory wildebeests. In general, we observed higher parasite diversity in younger wildebeests compared to older wildebeests. The decrease in parasite diversity in older individuals is well documented in helminths, and is deemed driven by the immune response elicited by repeated infections (Galvani 2005; Mutapi et al. 2008). These results contrasts with findings in other host taxa where parasite diversity is positively correlated to the age (Lo et al. 1998), suggesting that immunity and not exposure is limiting parasite infection patterns (Baird 1998; Peyerl-Hoffmann et al. 2001). Effect of Age on Gastrointestinal Helminths Prevalence and Intensity of Infection

The prevalence and intensity of infection with $\mathrm{H}$. placei, and $\mathrm{M}$. expansa was higher in juveniles than in sub-adults or adults. In livestock, juveniles are well known for less 
efficient protective immunity than adults against $\mathrm{H}$. placei and M. expansa, due to their limited exposure to these parasites (Kloosterman et al. 1991; Ploeger et al. 1995). However, C. raja was significantly more prevalent in older animals compared with younger ones, as already reported for paramphistomes in African cattle (Pfukenyi et al. 2005). It suggests that wildebeests do not particularly invest in immunity development to this parasite, and that older animals had simply more opportunities to encounter this long-lived parasite than young individuals.

Effect of Migration Time (or Different Migration Routes) on Parasites Infection Prevalence and Intensity Interestingly, the wildebeests arriving earlier or crossing through Mara Bridge had higher prevalence and intensity of infection than those arriving later to the Serena. This result suggests that either (1) early migrants originate from locations or use routes with a richer environmental parasitic infestation than late migrants, or (2) early migration is undertaken by individuals which are suffering from greater nutritional stress, in their areas of origin compared with late migrants (Holdo et al. 2009), and are therefore more vulnerable to parasite infection.

\section{Effect of Sex on Parasites Infection Prevalence and} Intensity

The sex of the hosts was important factor influencing the prevalence and intensity of helminth infection males were highly infected compared with females, in concordance with several studies report on sex-biased differences, loads/ burden, with males of many host species exhibiting higher parasitism than females (Poulin 1996). A sex bias in parasitism may be due to ecological, behavioural, or physiological differences between males and females (Zuk and McKean 1996). Specifically, males have higher levels of 716 D. Mijele et al. testosterone than females and testosterone is known to have immunosuppressive effects. In many polygynous species, males range widely than females, and such ranging behaviour can also expose males to heavier parasitic challenge (Zuk and McKean 1996).

\section{CONCLUSION}

The parasite species infecting migratory wildebeests are remarkably fewer than those found in non-migratory wildebeest (reported by previous studies) suggesting that long distance and massive migration is beneficial as a mechanism of parasite avoidance. Notwithstanding, due to the potential nutritional stress, migration could make early migrant wildebeests more prone to parasite infection. Most parasites recovered from migrating wildebeests were generalist parasites known to infect livestock, which is evidence of cross-infection along the migration routes. This result suggests that maintaining migration corridors for wildebeest free from livestock grazing may be wise policy in maintaining long-term health and conservation of both livestock and wildebeest, especially the most vulnerable young ones.

\section{ACKNOWLEDGMENTS}

The authors wish to thank the Director of Kenya Wildlife Service (KWS) and all the staff at KWS veterinary department for their assistance in data collection and 
analysis. We thank the Masai Mara National Reserve management particularly Dr. Asuka Takita and Mr. Brian Heath for their help in locating dead wildebeests along the Mara River and assisting in parasites samples collection. The authors thank Dr. Eberhard Zehle from the Africa Medical Research Foundation (AMREF) for helping in wildebeest post-mortem and collection of parasite samples. The authors also thank KWS for funding the research, and Sophia Masila for editing the manuscript.

\section{AUthoRs' CONTRIBUTIONS}

$\mathrm{DM}, \mathrm{PC}, \mathrm{MO}, \mathrm{SA}$, and TI conceived and designed the experiments for the paper. DM, PC, VO, LR, RCS, LR, RCS, SA have been involved in drafting the manuscript or revising it critically for important intellectual content. Manuscript was analyzed, discussed and written by all co-authors. All authors read and approved the final manuscript.

\section{Compliance With ETHICAL StandardS}

CONFLICT OF INTEREST The authors declare that there were no competing interests.

\section{REFERENCES}

Altizer S, Bartel R, Han BA (2011) Animal migration and infectious disease risk. Science 331:296-302

Attwell CAM (1980) Age determination of the blue wildebeest Connochaetes taurinus in Zululand. South African Journal of Zoology 15:121-130

Avgar T, Street G, Fryxell J (2013) On the adaptive benefits of mammal migration. Canadian Journal of Zoology 92:481-490 Baird JK (1998) Age-dependent characteristics of protection v. susceptibility to Plasmodium falciparum. Annals of Tropical Medicine and Parasitology 92:367-390

Beveridge I (1994) Family Anoplocephalidae cholodkovsky, 1902. In: Keys to the Cestode Parasites of Vertebrates, Khalil LF, Jones A, Bray RA (editors), Wallingford: CABI Publishing, pp 315366

Cattadori IM, Albert R, Boag B (2007) Variation in host susceptibility and infectiousness generated by co-infection: the myxomaTrichostrongylus retortaeformis case in wild rabbits. Journal of the Royal Society Interface 4:831-840 Cobey S, Lipsitch M (2013) Pathogen diversity and hidden regimes of apparent competition. The American naturalist 181:12 Crompton DWT (1973) The sites occupied by some parasitic helminths in the alimentary tract of vertebrates. Biological Reviews 48:27-83

Dash K (1973) The life cycle of Oesophagostomum columbianum (Curtice, 1890) in sheep. International Journal for Parasitology 3:843-851

Dobson RJ, Barnes EH (1995) Interaction between Ostertagia circumcincta and Haemonchus contortus infection in young lambs. International Journal for Parasitology 25:495-501 Dobson RJ, Barnes EH, Windon RG (1992) Population dynamics of Trichostrongylus colubriformis and Ostertagia circumcincta in single and concurrent infections. International Journal for Parasitology 22:997-1004

Dube S, Siwela A, Masanganise K, Dube C (2004) Abattoir studies on paramphistomes recovered from cattle from Maswingo and Manicaland provinces of Zimbabwe. Folia Vet 48:123-129 Durette-Desset MC (1983) Keys to genera of the superfamilies Trichistrongyroidea. In: CIH Keys to the Nematode Parasites of Vertebrates, Chabaud AG, Anderson RC, Willmott S (editors), Farnham Royal: Commonwealth Agricultural Bureaux Eduardo S (1983) The taxonomy of the family Paramphistomidae Fischoeder, 1901 with special reference to the morphology of species occurring in ruminants. III. Revision of the genus Calicophoron 
Na“smark, 1937. Systematic Parasitology 5:25-79

Fenton A, Perkins SE (2010) Applying predator-prey theory to modelling immune-mediated, within-host interspecific parasite interactions. Parasitology 137:1027-1038

Influence of Massive and Long Distance Migration on Parasite Epidemiology 717

Folstad I, Nilssen AC, Halvorsen O, Andersen J (1991) Parasite

avoidance: the cause of post-calving migrations in Rangifer?

Canadian Journal of Zoology 69:2423-2429

Galvani AP (2005) Age-dependent epidemiological patterns and strain diversity in helminth parasites. The Journal of Parasitology 91:24-30

Graham AL (2008) Ecological rules governing helminth-microparasite coinfection. Proceedings of the National Academy of

Sciences 105:566-570

Hausfater G, Meade BJ (1982) Alternation of sleeping groves by yellow baboons (Papio cynocephalus) as a strategy for parasite avoidance. Primates 23:287-297

Hawley DM, Altizer SM (2011) Disease ecology meets ecological immunology: understanding the links between organismal immunity and infection dynamics in natural populations. Functional Ecology 25:48-60

Holdo RM, Holt RD, Fryxell JM (2009) Opposing rainfall and plant nutritional gradients best explain the wildebeest migration in the Serengeti. The American Naturalist 173:431-445 Horak I, De Vos V, Brown MR (1983) Parasites of domestic and wild animals in South Africa. XVI. Helminth and arthropod parasites of blue and black wildebeest (Connochaetes taurinus and Connochaetes gnou). Onderstepoort Journal of Veterinary Research 50:243-255

Horak I, Meltzer D, De Vos V (1982) Helminth and arthropod parasites of springbok, Antidorcas marsupialis, in the Transvaal and western Cape Province. Onderstepoort Journal of Veterinary Research 49:7-10

Johns S, Shaw AK (2016) Theoretical insight into three diseaserelated benefits of migration. Population Ecology 58:213-221

Jones A (2005) Family fasciolidae railliet, 1895. Keys to the trematoda. In: Keys to the Trematoda, Vol 2, Jones A, Bray RA, Gibson DI (editors), Wallingford: CABI Publishing, pp 79-85 Junker K, Horak IG, Penzhorn B (2014) History and development of research on wildlife parasites in Southern Africa, with emphasis on terrestrial mammals, especially ungulates. International Journal for Parasitology: Parasites and Wildlife 4:50-70 Kloosterman A, Albers GAA, Van den Brink R (1984) Negative interactions between Ostertagia ostertagi and Cooperia oncophora in calves. Veterinary parasitology 15:135-150

Kloosterman A, Frankena K (1988) Interactions between lungworms and gastrointestinal worms in calves. Veterinary parasitology 26:305-320

Kloosterman A, Ploeger HW, Frankena K (1990) Increased establishment of lungworms after exposure to a combined infection of Ostertagia ostertagi and Cooperia oncophora. Veterinary parasitology 36:117-122

Kloosterman A, Ploeger HW, Frankena K (1991) Age resistance in calves to Ostertagia ostertagi and Cooperia oncophora. Veterinary parasitology 39:101-113

Lichtenfels JR (1980) Keys to genera of the superfamilies

Strongyroidea. In: CIH Keys to the Nematode Parasites of Vertebrates,

Anderson RC, Chabaud AG, Willmott S (editors),

Farnham Royal: Commonwealth Agricultural Bureaux

Lichtenfels JR, Pilitt PA, Hoberg P (1994) New morphological characters for identifying individual specimens of Haemonchus spp. (Nematoda: Trichostrongyloidea) and a key to species in ruminants of North America. Journal of Parasitology 78:E1-E11 Lo CM, Morand S, Galzin R (1998) Parasite diversitylhost age and size relationship in three coral-reef fishes from French Polynesia. International Journal for Parasitology 28:1695-1708

Lone BA, Chisti MZ, Ahmad F, Tak H (2011) Serodiagnosis of Oesophagostomum Columbianum infection in Goats using 
indirect ELISA. Veterinary World 4:503-506

Mideo N (2009) Parasite adaptations to within-host competition.

Trends in Parasitology 25:261-268

Mijele D, Obanda V, Omondi P, Soriguer RC, Gakuya F, Otiende M, Hongo P, Alasaad S (2013) Spatio-temporal distribution of injured elephants in Masai Mara and the putative negative and positive roles of the local community. PloS One 8:e71179 Mutapi F, Burchmore R, Mduluza T, Midzi N, Turner CMR, Maizels RM (2008) Age-related and infection intensity-related shifts in antibody recognition of defined protein antigens in a schistosome-exposed population. Journal of Infectious Diseases 198:167-175

Nwosu CO, Ogunrinade AF, Fagbemi BO (1996) Prevalence and seasonal changes in the gastro-intestinal helminths of Nigerian goats. Journal of Helminthology 70:329-333

Pedersen AB, Fenton A (2007) Emphasizing the ecology in parasite community ecology. Trends in ecology \& evolution 22:133139

Peyerl-Hoffmann G, Jelinek T, Kilian A, Kabagambe G, Metzger WG, Von Sonnenburg F (2001) Genetic diversity of Plasmodium falciparum and its relationship to parasite density in an area with different malaria endemicities in West Uganda. Tropical Medicine \& International Health 6:607-613 Pfukenyi DM, Mukaratirwa S, Willingham AL, Monrad J (2005) Epidemiological studies of amphistome infections in cattle in the highveld and lowveld communal grazing areas of Zimbabwe. Onderstepoort Journal of Veterinary Research 72:67-86 Piersma T (1997) Do global patterns of habitat use and migration strategies co-evolve with relative investments in immunocompetence due to spatial variation in parasite pressure? Oikos

80:623-631

Ploeger HW, Kloosterman A, Rietveld FW (1995) Acquired immunity against Cooperia spp. and Ostertagia spp. in calves: effect of level of exposure and timing of the midsummer increase. Veterinary parasitology 58:61-74

Popova TI (1958) Essentials of Nematodology. Strongyloids of Animals and Man: Trichonematidae (Translated by Artman M., Israel Program for Scientific Translations (1965)), Moscow: Academy of Science of the USSR

Poulin R (1996) Sexual inequalities in helminth infections: a cost of being a male? American Naturalist 147:287-295

R Core Team (2014) R: a language and environment for statistical computing, Vienna, Austria: R Foundation for Statistical Computing Roeber F, Jex AR, Gasser RB (2013) Impact of gastrointestinal parasitic nematodes of sheep, and the role of advanced molecular tools for exploring epidemiology and drug resistance-an Australian perspective. Parasites Vectors 6:153 Schmidt GD (1986) CRC handbook of tape worm identification, Boca Raton, Florida: CRC Press, pp 675

Sutherland I, Scott I (2009) Gastrointestinal nematodes of sheep and cattle: biology and control, Chichester: Wiley

Talbot LM, Talbot MH (1963) The Wildebeest in Western Masailand, East Africa. Wildlife Monographs, New York: Wiley, pp 3-88

Tariq KA, Chishti MZ, Ahmad F, Shawl AS (2008) Epidemiology of gastrointestinal nematodes of sheep managed under traditional husbandry system in Kashmir valley. Veterinary Parasitology 158:138-143

718 D. Mijele et al.

Telfer S, Lambin X, Birtles R, Beldomenico P, Burthe S, Paterson S, Begon M (2010) Species interactions in a parasite community drive infection risk in a wildlife population. Science 330:243-246 Ulrich Y, Schmid-Hempel P (2012) Host modulation of parasite competition in multiple infections. Proceedings of the Royal Society B 279:2982-2989

Zuk M, McKean KA (1996) Sex differences in parasite infections: patterns and processes. International Journal for Parasitology 26:1009-1024 